\title{
The Synthesis of Microporous Carbon in the Furfural-Hydroquinone-Urotropin System
}

\author{
A.V. Melezhik*, A.D. Zelenin, O.V. Alekhina, N.R. Memetov, A.G. Tkachev \\ Tambov State Technical University, \\ 106, Sovetskaya St., Tambov, 392000, Russia \\ * Corresponding author. Tel.: +7 47526392 93. E-mail: nanocarbon@rambler.ru
}

\begin{abstract}
The mutual solubility and polymerization in the furfural-hydroquinone-urotropin system were studied. Microporous carbon was obtained by activating the carbonized polymer with potassium hydroxide. It has been found that, depending on the mass ratio of $\mathrm{KOH}$ to carbonizing polymer, the specific surface area of the activated carbon varies from 2010 to $3307 \mathrm{~m}^{2} / \mathrm{g}$, and the micropore volume varies from 0.941 to $1.124 \mathrm{~cm}^{3} / \mathrm{g}$. The surface and porosity parameters of model carbon structures with homogeneous square or hexagonal pores were calculated. It is assumed that the micropore volume of the obtained activated carbons is approaching the theoretical limit. The resulting coals can be used as effective adsorbents.
\end{abstract}

\section{Keywords}

Microporous carbon; carbonization; polymerization; surface area; adsorbents.

(C) A.V. Melezhik, A.D. Zelenin, O.V. Alekhina, N.R. Memetov, A.G. Tkachev, 2020

\section{Introduction}

Microporous carbon materials are widely used in technology as adsorbents for air and water purification, in medicine, in chemical current sources, for methane storage, and in other fields of technology. Carbon materials with the highest possible specific micropore volume are required for the most efficient use.

The most common way to obtain activated carbons is the activation of various carbon-containing raw materials (carbonization products of plant materials, organic polymers) with water vapor, carbon dioxide, and various chemical reagents [1]. Thus, the adsorption properties of AC-1 activated carbon obtained by vaporgas activation of a carbonized coconut shell were studied in [2]. The specific micropore volume for this coal was $0.62 \mathrm{~cm}^{3} / \mathrm{g}$.

The adsorption properties of AC-5 activated carbon obtained from furfural by thermochemical synthesis of a carbon matrix were studied in [3]. The authors do not give details of the synthesis procedure, however, it can be assumed that it involves the synthesis of a furfural-based polymer, its carbonization and gas-phase activation (usually the activation of such materials is carried out with water vapor, carbon dioxide or their mixture). The specific micropore volume for this coal was $0.53 \mathrm{~cm}^{3} / \mathrm{g}$.

The adsorption properties of activated carbons obtained by various methods are described in [4]. In particular, the data on the specific micropore volume for these coals are given. Coals AC-1, AC-2, AC-4, AC-6, AC-7 were obtained by carbonization and activation of plant materials (coconut shell, natural coal). Coals AC-5 and PAH-10 are obtained by carbonization and activation of polymers, furfural and polyvinylidene chloride respectively. The structural and energy characteristics of these adsorbents were determined from the adsorption isotherms of standard benzene vapor at temperatures of 293-298 K using the Dubinin-Radushkevich equation. For these coals, the specific micropore volume does not exceed $0.62 \mathrm{~cm}^{3} / \mathrm{g}$. A small micropore volume limits the use of activated carbons, in particular, for methane storage, where the maximum possible micropore volume per unit volume of adsorbent is required.

Higher surface and porosity indicators are achieved by chemical activation of carbon-containing materials with potassium hydroxide at high temperature [5-13]. This method is applicable to a wide variety of 
carbon-containing materials. If plant or polymer raw materials are used, they are first subjected to heat treatment (carbonization), usually at temperatures in the range of $300-550{ }^{\circ} \mathrm{C}$. Then the carbonized product is mixed with solid potassium hydroxide or soaked in a solution of potassium hydroxide and further dried. Then the mixture is heated in an inert atmosphere (nitrogen or argon) to a temperature of $600-900{ }^{\circ} \mathrm{C}$. After heat treatment and cooling, the reaction mixture is poured with water, and the activated carbon material is washed from water-soluble substances (excess alkali, potassium carbonate) and dried. The post-treatment of activated carbon material is often supplemented by treatment with an acid solution and repeated washing with water for more complete removal of mineral impurities.

In a number of studies, potassium hydroxide activation was used specifically for the synthesis of microporous carbon adsorbents optimized for methane adsorption and storage. Thus, in [12] methane adsorption was studied on several microporous materials, including Maxsorb activated carbon material manufactured by the Japanese company Kansai Coke and Chemicals. According to the available publications, this material is obtained by high-temperature activation of the carbon precursor material with a potassium hydroxide melt. In general, various publications mention different Maxsorb modifications with slightly different parameters. In this paper, the specific surface area of BET for the Maxsorb material is $3080 \mathrm{~m}^{2} / \mathrm{g}$.

Several carbon materials obtained by hightemperature activation of carbon precursor materials by a potassium hydroxide melt were studied in [14]. The activated materials have a BET specific surface area in the range of $3100-3380 \mathrm{~m}^{2} / \mathrm{g}$.

In [15], for the active carbon Maxsorb III, produced by the same Japanese company, the following data are presented: specific surface area according to BET $-2805 \mathrm{~m}^{2} / \mathrm{g}$, specific pore volume $-1.58 \mathrm{~cm}^{3} / \mathrm{g}$. The pore width distribution was a complex curve in the range of $0.6-3.5 \mathrm{~nm}$ (with a small tail in the region of $3.5-4.3 \mathrm{~nm}$ ) with several maxima.

In [16], for the carbon material Maxsorb-III, the BET specific surface area is $3140 \mathrm{~m}^{2} / \mathrm{g}$ and the specific pore volume is $1.7 \mathrm{~cm}^{3} / \mathrm{g}$.

In [17], the activated carbon Maxsorb III of the same manufacturer, Kensi Coke and Chemicals Co. Ltd., Osaka Japan, was studied as a methane adsorbent. The article gives the following characteristics of this carbon material: the specific surface area by BET is $3311 \mathrm{~m}^{2} / \mathrm{g}$, the specific micropore volume according to Dubinin-Astakhov is $1.870 \mathrm{~cm}^{3} / \mathrm{g}$, the total pore volume by NLDFT equals $1.743 \mathrm{~cm}^{3} / \mathrm{g}$, and the pore width by NLDFT is $2.2 \mathrm{~nm}$ or $1.82 \mathrm{~nm}$ according to Dubinin-Astakhov.
The following characteristics of the same material are given in [18]: the specific surface area by BET equals $3276 \mathrm{~m}^{2} / \mathrm{g}$, the specific micropore volume is $1.79 \mathrm{~cm}^{3} / \mathrm{g}$, and the average pore diameter is $2.085 \mathrm{~nm}$. As it can be seen, the data for the same material from different researchers are somewhat different from each other.

In [19], several carbon samples with a developed surface were obtained by high-temperature activation of anthracite by a potassium hydroxide melt (in different modes) and were characterized by the specific BET surface area from 1998 to $3790 \mathrm{~m}^{2} / \mathrm{g}$ depending on the activation mode.

In [10], the active carbon was obtained with the BET specific surface area of $3227 \mathrm{~m}^{2} / \mathrm{g}$, the pore volume of $1.829 \mathrm{~cm}^{3} / \mathrm{g}$ and the pore size of $1.7-2.2 \mathrm{~nm}$. The synthesis of this carbon included the preliminary carbonization of corn cobs at temperatures up to $450{ }^{\circ} \mathrm{C}$ in an inert atmosphere. Depending on the activation modes (mass ratio of potassium hydroxide and carbonized raw materials, activation temperature), the BET specific surface area for the obtained activated carbon materials was $1967-3227 \mathrm{~m}^{2} / \mathrm{g}$. A sample with the highest specific surface area $\left(3227 \mathrm{~m}^{2} / \mathrm{g}\right)$ was obtained with the activation temperature of $850^{\circ} \mathrm{C}$ and the $\mathrm{KOH}$ mass ratio to carbonized at $450{ }^{\circ} \mathrm{C}$ raw materials equal to $4: 1$. This sample was also characterized by the highest total specific pore volume $\left(1.892 \mathrm{~cm}^{3} / \mathrm{g}\right)$. The average pore width was $1.17 \mathrm{~nm}$.

In [9], the carbon material with the high specific surface area was obtained by activating mesocarbon beads from potassium hydroxide at $800^{\circ} \mathrm{C}$. Under optimal activation conditions, the specific surface area by BET (nitrogen) was $2978 \mathrm{~m}^{2} / \mathrm{g}$, and the specific micropore volume was $1.48 \mathrm{~cm} 3 / \mathrm{g}$.

A common disadvantage of the known carbon materials obtained by activation with potassium hydroxide is that, as a rule, along with micropores, a significant volume of mesopores is present. If the task is to obtain the maximum micropore volume per adsorbent volume, which is required, for example, for methane storage systems, then the presence of mesopores does not allow fulfilling this task.

The aim of this work is to develop a method for the synthesis of carbon material with the maximum possible specific volume of micropores.

\section{Experimental}

In the present work, the following source materials were used.

Furfural, Ch brand, GOST 10930-74.

Hydroquinone premium, GOST 19627-74.

Urotropin, ChDA brand, TU 2478-037-002038032012. 
Potassium hydroxide, ChDA brand, in the form of granules with the $\mathrm{KOH}$ content of $85 \%$ (the rest is water).

To determine the areas of mutual solubility and polymerization, calculated weighed fractions of furfural, hydroquinone and urotropin were placed in the test tubes and sealed with aluminum foil. The number of components was taken so that the height of the mixture layer in the tubes did not exceed $5 \mathrm{~mm}$, which allowed to do the experiment without mixing. A thermostat with a temperature of $130{ }^{\circ} \mathrm{C}$ was placed into the packet of filled tubes. After 1 hour, the presence or absence of precipitate was visually determined. If the color of the solution was too dark, the presence of precipitate was determined by sampling with a wire loop. Then, the temperature in the thermostat was raised to $150{ }^{\circ} \mathrm{C}$ and the samples were kept for another 1 hour, after which the consistency of the mixture in hot form and after cooling to room temperature was determined using a wire probe. Thus, the polymerization rate, which was evaluated in points according to the following features, was analyzed:

5 - solid polymer at $150{ }^{\circ} \mathrm{C}$;

4 - viscous resin at $150{ }^{\circ} \mathrm{C}$, solid resin at $20^{\circ} \mathrm{C}$;

3 - liquid at $150{ }^{\circ} \mathrm{C}$, viscous resin at $20^{\circ} \mathrm{C}$

2 - not viscous liquid at $150^{\circ} \mathrm{C}$, viscous liquid at $20{ }^{\circ} \mathrm{C}$;

1 - not viscous liquid at $150{ }^{\circ} \mathrm{C}$, the same at $20^{\circ} \mathrm{C}$.

The range of compositions in which the polymerization rate was 1 or 2 points was considered technologically unacceptable.

For activation experiments, the selected mixtures of furfural, hydroquinone, and urotropin mixtures were prepared and heated in a heat-resistant glass for 30 minutes at $130^{\circ} \mathrm{C}$. At the beginning the mixtures were stirred until the solid components were dissolved, then the glasses closed with aluminum foil were kept for 8 hours at $150{ }^{\circ} \mathrm{C}, 8$ hours at $300{ }^{\circ} \mathrm{C}$ and 8 hours at $400{ }^{\circ} \mathrm{C}$. The resulting solid polymers were ground to pass them through a $0.5 \mathrm{~mm}$ sieve.

The activation was carried out as follows. After heat treatment at $400{ }^{\circ} \mathrm{C}(5 \mathrm{~g})$, a polymer portion was placed in a steel glass with an inner diameter of $68 \mathrm{~mm}$ and a height of $88 \mathrm{~mm}$, and potassium hydroxide granules were added. The glass was purged with argon and closed with a lid with an annular lock through which argon was passed during the activation to isolate the reaction zone from the atmosphere. This assembly was heated in a muffle furnace up to $750{ }^{\circ} \mathrm{C}$ and held for 3 hours at this temperature. After cooling to room temperature, the reaction mixture was poured with water, the precipitate was washed from alkali to a neutral $\mathrm{pH}$, then it was kept for one day with hydrochloric acid to dissolve metal impurities, washed again with water and dried at $110{ }^{\circ} \mathrm{C}$ to constant weight. Further, the resulting activated microporous carbon materials will be designated as MPC (2), MPC (2.5), and MPC (4), where the figure indicates the mass ratio of potassium hydroxide $(85 \%)$ to the source polymer.

The surface and porosity parameters were measured by nitrogen adsorption at $77 \mathrm{~K}$ using an Autosorb-iQ instrument (Quantachrome Instruments). To calculate the surface and porosity parameters, mathematical models integrated into the instrument software were used. In this case, the best agreement with the experiment was observed for the calculation model " $\mathrm{N}_{2}$ on carbon at $77 \mathrm{~K}$, slit/cylindrical pore, NLDFT equilibrium model". Further in the text, the designation DFT implies this calculation model.

\section{Results and Discussion}

In $[20,21]$, the authors describe a method for producing active carbons from a furfural-based polymer with the addition of epoxy resin (with a small amount of sulfuric acid as a polymerization catalyst) by carbonizing this polymer with subsequent gas-phase activation with water vapor. Depending on the activation mode (degree of burnout), the specific micropore volume for the obtained activated carbons is $0.293-0.80 \mathrm{~cm}^{3} / \mathrm{g}$, and the mesopore volume is $0.367-0.701 \mathrm{~cm}^{3} / \mathrm{g}$.

In [22], mesoporous carbon materials with the specific surface area by BET equal to 2600 and $2900 \mathrm{~m}^{2} / \mathrm{g}$, with the total pore volume of 3.39 and $3.68 \mathrm{~cm}^{3} / \mathrm{g}$ and the micropore volume of 0.47 $0.31 \mathrm{~cm}^{3} / \mathrm{g}$, respectively, were obtained from the mixture of furfural with hydroquinone by its carbonization and activation in a melt of sodium and potassium hydroxides.

Thus, it can be concluded that furfural-based polymers are promising for the synthesis of carbon materials with a developed surface, due to the fact that these polymers are characterized by a large coke residue during carbonization.

Our experiments showed that upon heating binary mixtures of furfural-hydroquinone or furfural-urotropin at $130-150{ }^{\circ} \mathrm{C}$, polymerization (or polycondensation) in the absence of acidic or alkaline catalysts does not occur, in any case, its rate is unacceptably low for technological applications. However, in the ternary system furfural-hydroquinone-urotropin, polymerization proceeds quite quickly. As far as we know, this system has not been studied before. We investigated this system using the techniques described above in the experimental part. 


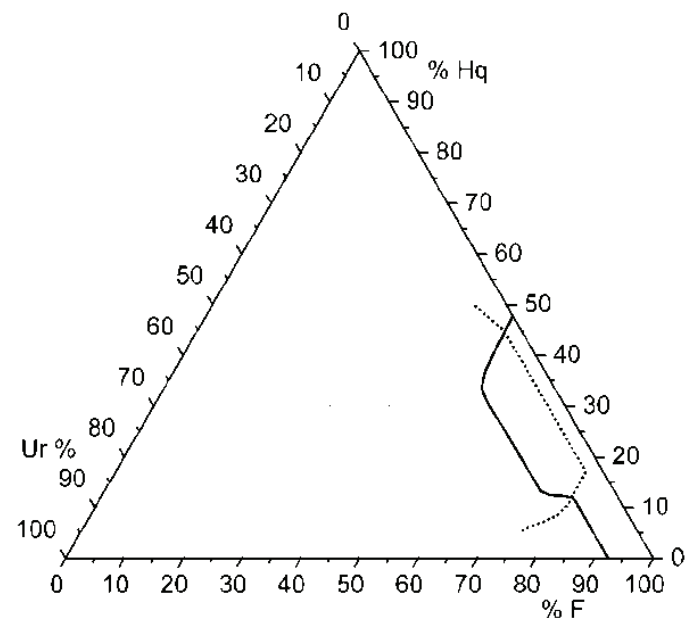

Fig. 1. Areas of complete mutual solubility (to the right of the solid line) and polymerization (to the left of the dashed line) in the diagram of furfural-hydroquinone-urotropin compositions

Fig. 1 shows a triple diagram of the compositions of furfural-hydroquinone-urotropin built on the basis 50 compounds which were studied experimentally. The solid line limits the area of complete mutual solubility of the components at $130^{\circ} \mathrm{C}$, and the dashed line indicates the area in which polymerization at $150{ }^{\circ} \mathrm{C}$ proceeds at a technologically acceptable rate (more than 2 points according to the above rating scale). The intersection of these areas gives a range of compositions that can be used to synthesize carbon materials.

The data on the specific surface area and porosity values for activated carbon material obtained from the polymer composition of the range shown in Fig. 1 are presented below.

Fig. 2 show nitrogen adsorption-desorption isotherms and the differential and integral pore size distributions according to the DFT model for samples of activated materials MPC (2), MPC (2.5), and MPC (4). The nitrogen vapor sorption-desorption isotherms on samples MPC (2) and MPC (2.5) belong to the first (I) type according to the IUPAC classification, which is characteristic of microporous materials with a small proportion of mesopores. With an increase in the mass ratio of potassium hydroxide to the source polymer to $4: 1$ (MPC (4) material), the specific volume and size of mesopores significantly increase, which affects the shape of the adsorption-desorption isotherm.

Table 1 shows the parameters of the specific surface and porosity of the synthesized materials.

The table shows that with an increase in the mass ratio of potassium hydroxide to the source polymer, the yield of activated material decreases due to greater carbon burnout upon activation. In this case, the specific surface area by BET and DFT and the specific pore volume by DFT increase. Apparently, for those applications where the maximum possible micropore volume per unit volume of adsorbent is required, the MPC (2) and MPC (2.5) samples are close to optimal.

To understand the maximum possible parameters of the specific surface and porosity, one can consider model honeycomb carbon structures built of identical tightly laid parallel tubular pores of square or hexagonal cross section with walls separating them with a thickness of one graphene layer. In this case, the effective pore width will be considered the distance between the opposite walls of a square or hexagonal pore. Suppose also that all pores are open and the pore length is much larger than the width, so that the mass of the "plugs" can be neglected. To estimate the effective thickness and mass of graphene walls, we will proceed from the crystallographic density of graphite $\left(2.260 \mathrm{~g} / \mathrm{cm}^{3}\right)$ and the interlayer distance of graphene layers in graphite $(0.3354 \mathrm{~nm})$.

Obviously, these assumptions are not fulfilled in practice, but they give the maximum possible parameter values for ideal carbon materials. Under these assumptions, the following expressions are obtained for the parameters of model materials:

$$
\begin{aligned}
& S=4 a[2.260 t(t+2 a)]^{-1} ; \\
& v=a[2.260 t(t / a+2)]^{-1} ; \\
& d=2.260 t(t+2 a)(a+t)^{-2} ; \\
& v / V=v d,
\end{aligned}
$$

where $S$ - specific surface area, $\mathrm{cm}^{2} / \mathrm{g} ; v$ - specific pore volume, $\mathrm{cm}^{3} / \mathrm{g} ; d-$ material density, $\mathrm{g} / \mathrm{cm}^{3} ; v / V-$ fraction of pore volume in the total material volume, $\mathrm{cm}^{3} / \mathrm{cm}^{3} ; a$-pore width, $\mathrm{cm} ; t$ - thickness of the walls separating the pores, taken equal to one graphene layer, $0.3354 \cdot 10^{-7} \mathrm{~cm} ; 2.260$ - crystallographic density of graphite (dimension $\mathrm{g} / \mathrm{cm}^{3}$ is assumed).

Table 2 shows the numerical results of the parameters calculation.

The same results for pores of square and hexagonal sections are explained by the fact that, according to the well-known geometric theorem, the area of a polygon circumscribed around a circle is equal to a quarter of the product of the polygon perimeter by the inscribed circle diameter, regardless of the number of the polygon sides. In our case, the circle diameter is equal to the pore width, the perimeter multiplied by the pore length is equal to the pore surface, and the perimeter multiplied by the wall thickness, pore length and density is equal to the mass of the material regardless of the number of the polygon sides under the condition of dense pore packing. 


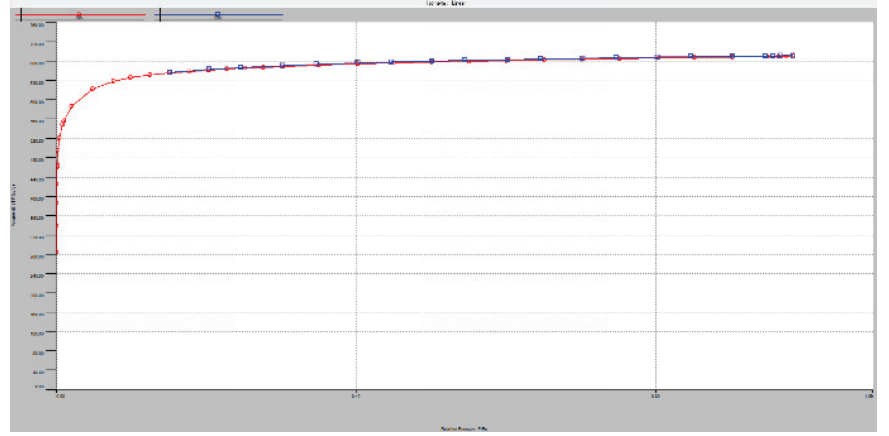

a)

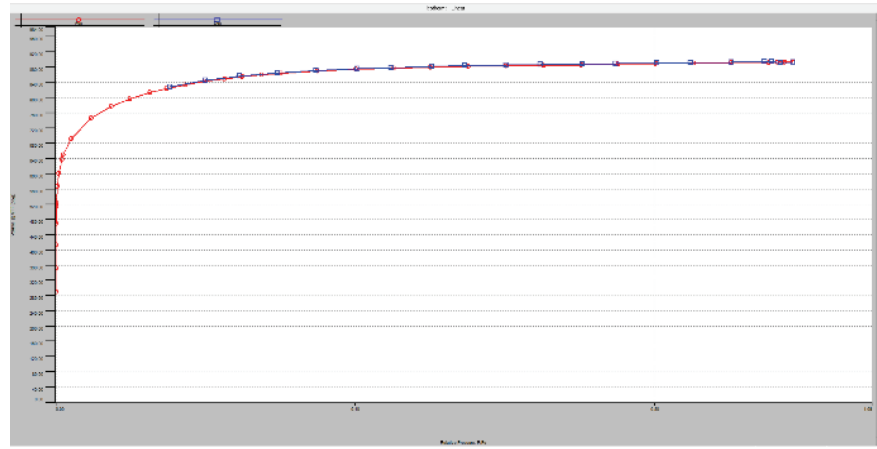

c)

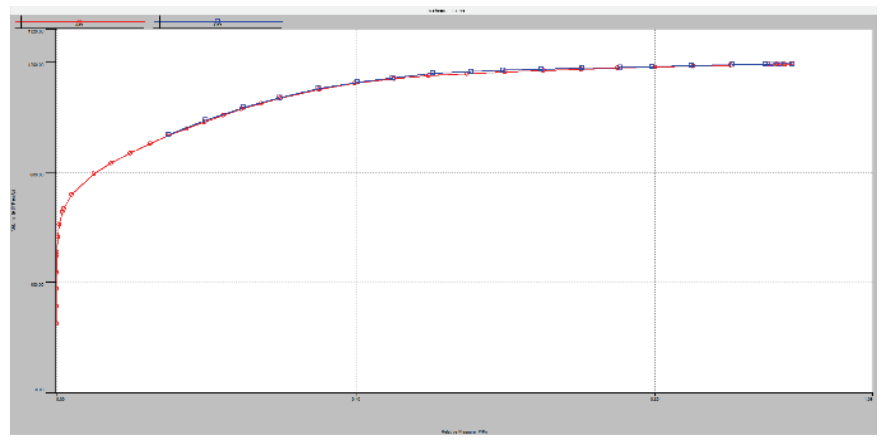

e)

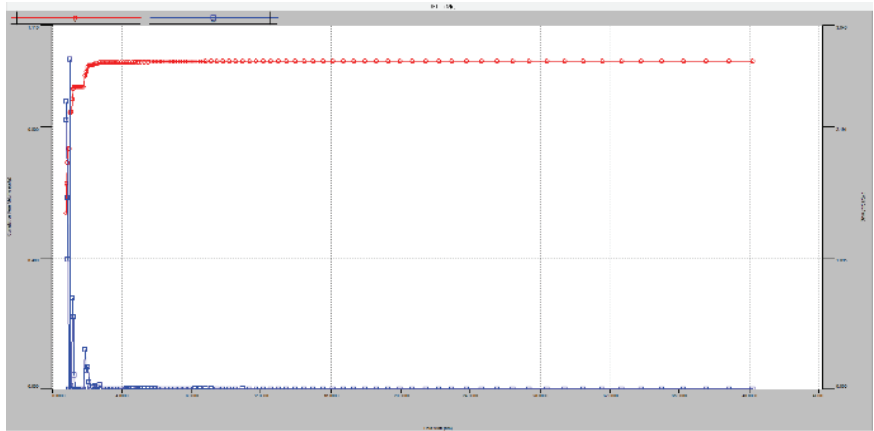

b)

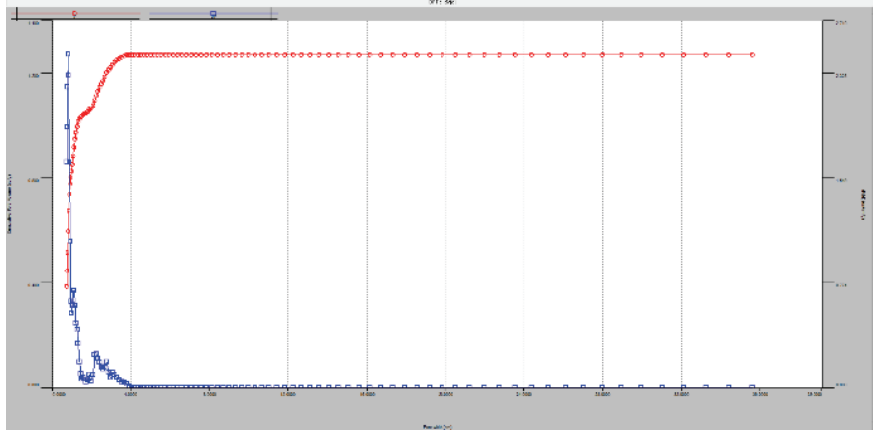

d)

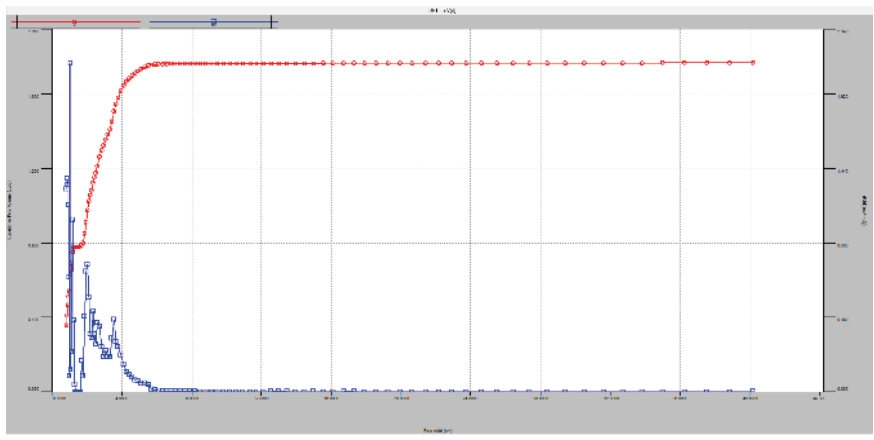

f)

Fig. 2. Nitrogen adsorption-desorption isotherms $(77 \mathrm{~K})(a, c, e)$ and differential and integral pore diameter distributions (DFT) $(b, d, f)$ for MPC sample:

$a, b-2 ; c, d-2.5 ; e, f-4$

Table 1

Surface and porosity parameters of activated carbon materials

\begin{tabular}{rcccccc}
\hline Sample & $Y, \%$ & $S \mathrm{BET}, \mathrm{m}^{2} / \mathrm{g}$ & $S \mathrm{DFT}, \mathrm{m}^{2} / \mathrm{g}$ & $V \mathrm{DFT}, \mathrm{cm}^{3} / \mathrm{g}$ & $V(<2 \mathrm{~nm}) \mathrm{DFT}, \mathrm{cm}^{3} / \mathrm{g}$ & $V \mathrm{DR}_{\mathrm{cm}} / \mathrm{g}$ \\
\hline MPC (2) & 51.5 & 2010 & 2545 & 1.001 & 0.975 & 1.039 \\
MPC (2.5) & 47.4 & 2625 & 3035 & 1.307 & 1.124 & 1.263 \\
MPC (4) & 35.6 & 3307 & 3359 & 1.769 & 0.941 & 1.366 \\
\hline
\end{tabular}

Node. $Y=$ Yield of activated material, \% from starting one; $S=$ BET or DFT specific surface area; $V$ DFT $=$ DFT specific pore volume; $V(<2 \mathrm{~nm})$ DFT $=$ DFT specific pore volume for pores with size $<2 \mathrm{~nm}$ (micropores); $V$ DR = specific micropore volume by Dubinin-Radushkevich. 
Table 2

\section{Surface and porosity parameters of ideal carbon materials, calculated on the basis of the made assumptions, for a model \\ of tubular pores of square or hexagonal section, with different pore widths $(a, \mathrm{~nm})$}

\begin{tabular}{ccccc}
\hline$a, \mathrm{~nm}$ & $S, \mathrm{~m}^{2} / \mathrm{g}$ & $v, \mathrm{~cm}^{3} / \mathrm{g}$ & $d, \mathrm{~g} / \mathrm{cm}^{3}$ & $v / V, \mathrm{~cm}^{3} / \mathrm{cm}^{3}$ \\
\hline$\infty$ & 2638 & $\infty$ & 0 & 1 \\
5 & 2553 & 3.1911 & 0.2752 & 0.8782 \\
4.5 & 2544 & 2.8617 & 0.3026 & 0.8660 \\
4 & 2532 & 2.5323 & 0.3362 & 0.8513 \\
3.5 & 2518 & 2.2031 & 0.3780 & 0.8328 \\
3 & 2499 & 1.8741 & 0.4317 & 0,8090 \\
2.5 & 2473 & 1,5454 & 0.5030 & 0.7773 \\
2 & 2434 & 1,2172 & 0.6025 & 0.7334 \\
1.5 & 2373 & 0.8899 & 0.7505 & 0.6679 \\
1 & 2260 & 0.5649 & 0.9927 & 0.5608 \\
\hline
\end{tabular}

All obtained values have a simple physical meaning. With increasing pore size with a constant wall thickness, the specific surface area, specific pore volume and pore volume, referred to the volume of the material, increase. The density of the material decreases. It is useful to keep these data in mind for assessing whether there are still reserves for improving certain specific materials or methods of synthesis, or whether the parameters are close to the theoretical limit and further improvement is impossible. According to the results of calculating the ideal structure (Table 1), at a pore width of $2 \mathrm{~nm}$, the specific pore volume is $1.2172 \mathrm{~cm}^{3} / \mathrm{g}$, which is the upper limit for real substances. The synthesized material MPC (2.5) with a specific micropore volume of $1.124 \mathrm{~cm}^{3} / \mathrm{g}$ approaches the theoretically possible limit. Apparently, the Dubinin-Radushkevich method for the MPC (4) material gives an overestimated value of the specific micropore volume $\left(1.366 \mathrm{~cm}^{3} / \mathrm{g}\right)$.

\section{Conclusion}

Thus, a method for the synthesis of predominantly microporous carbon materials with a high specific micropore volume, based on carbonization and activation of the polymer furfural-hydroquinoneurotropin with potassium hydroxide, was developed. These materials may find application, for example, in methane storage systems.

\section{References}

1. Kienle von H., Bader E. Aktivnye Ugli $i$ ih Promyshlennoe Primenenie [Active carbons and their industrial applications]. Khimiya, 1980, 216 p.

2. Strizhenov E.M., Fomkin A.A., Zherdev A.A., Pribylov A.A. Adsorbtsiya Metana na Mikroporistom Uglerodnom Adsorbente AU-1 [Adsorption of methane on microporous carbon adsorbent AC-1]. Phisikokhimia poverkhnosti i zaschita materialov, 2012, 48(6), 521-526. (Rus)

3. Strizhenov E.M., Shkolin A.V., Fomkin A.A., Pribylov A.A., Zherdev A.A., Smirnov I.A. Adsorbtsiya Metana na Mikroporistom Uglerodnom Adsorbente AU-5 [Adsorption of methane on microporous carbon adsorbent AC-5]. Phisikokhimia poverkhnosti $i$ zaschita materialov, 2013, 49(5), 483-490. (Rus)

4. Menschikov I.E., Fomkin A.A., Arabei A.B., Shkolin A.V., Strizhenov E.M. Opisanie Adsorbcii Metana na Mikroporistyh Uglerodnyh Adsorbentah $v$ Oblasti Sverhkriticheskih Temperatur na Osnove Uravneniya Dubinina-Astahova [Description of adsorption of methane on microporous carbon adsorbents in the region of supercritical temperatures based on Dubinin-Astakhov equation]. Phisikokhimia poverkhnosti i zaschita materialov, 2016, 52(4), 339-344. (Rus)

5. Jiménez V., Sánchez P., Valverde J.L., Romero A. Influence of the Activating Agent and the Inert Gas (Type and Flow) Used in an Activation Process for the Porosity Development of Carbon Nanofibers. Journal of Colloid and Interface Science, 2009, 336, 712-722.

6. Lozano-Castello D., Calo J.M., Cazorla-Amoros D., Linares-Solano A. Carbon Activation with $\mathrm{KOH}$ as Explored by Temperature Programmed Techniques, and the Effects of Hydrogen. Carbon, 2007, 45, 2529-2536.

7. Fierro V., Torne-Fernandez V., Celzard A. Highly Microporous Carbons Prepared by Activation of Kraft Lignin with KOH. Studies in Surface Science and Catalysis, 2007, 160, p607-614.

8. Hayashi J., Uchibayashi M., Horikawa T., Muroyama K., Gomes V.G. Synthesizing Activated Carbons from Resins by Chemical Activation with $\mathrm{K}_{2} \mathrm{CO}_{3}$. Carbon, 2002, 40, 2747-2752.

9. Chen X.S., McEnaney B., Mays T.J., AlcanizMonge J., Cazorla-Amoros D., Linares-Solano A. Theoretical and Experimental Studies of Methane Adsorption on Microporous Carbons. Carbon, 1997, 35(9), 1251-1258.

10. Liu B., Wang W., Wang N, Chak Tong Au (Peter). Preparation of Activated Carbon with High Surface Area for High-capacity Methane Storage. Journal of Energy Chemistry, 2014, 23(5), 662-668.

11. Otowa T., Tanibata R., Itoh M. Production and Adsorption Characteristics of MAXSORB: High-surfacearea Active Carbon. Gas Separation \& Purification, 1993, 7(4), 241-245.

12. García Blanco A.A., Vallone A.F., Korili S.A., Gil A., Sapag K. A Comparative Study of Several Microporous Materials to Store Methane by Adsorption. Microporous and Mesoporous Materials, 2016, 224, 323-331. 
13. Aukett P.N., Quirke N., Riddiford S., Tennison S.R. Methane Adsorption on Microporous Carbons a Comparison of Experiment, Theory, and Simulation. Carbon, 1992, 30(6) 913-924.

14. Ganesan A., Shaijumon M.M.. Activated Graphenederived Porous Carbon with Exceptional Gas Adsorption Properties. Microporous and Mesoporous Materials, 2015, doi:10.1016/j.micromeso.2015.08.021.

15. Kayal S., Chakraborty A. Activated Carbon (Type Maxsorb-III) and MIL-101(Cr) Metal Organic Framework Based Composite Adsorbent for Higher $\mathrm{CH}_{4}$ Storage and $\mathrm{CO}_{2}$ Capture. Chemical Engineering Journal, 2018, 334, 780-788.

16. Saha B.B., Srinivasan K., Chakraborty A., Khairul H., El-Sharkawy I.I., Shigeru K. Adsorption Characteristics of Maxsorb-III + Methane Systems by Desorption Experiments. Proceedings of IMECE2007 2007 ASME International Mechanical Engineering Congress and Exposition, November 11-15, 2007, Seattle, Washington, USA. IMECE 2007-42941.

17. Thu K., Kim Y.-D., Ismil A.B., Saha B.B., Kim Ch.N. Adsorption Characteristics of Methane on Maxsorb III by Gravimetric Method. Applied Thermal Engineering, 2014, 72, 200-205.

18. Patil K.H., Sahoo S., Charge Characteristics of Adsorbed Natural Gas Storage System Based on MAXSORB
III. Journal of Natural Gas Science \& Engineering, 2018, doi: 10.1016/j.jngse.2018.01.008.

19. Alcañiz-Monge J., Lozano-Castelló D., CazorlaAmorós D., Linares-Solano A. Fundamentals of Methane Adsorption in Microporous Carbons. Microporous and Mesoporous Materials, 2009, 124, 110-116.

20. Tsivadze A.Yu., Gur'yanov V.V., Petukhova G.A. Poluchenie, Svojstva i Perspektivy Primeneniya Sfericheskih Aktivnyh Uglej na Osnove Furfurola v Narodnom Hozyajstve $i$ Medicine [Production, properties and perspectives of application of spherical active carbons based on furfural in industry and medicine]. Phisikokhimia poverkhnosti I zaschita materialov, 2011, 47(5), 508-516. (Rus)

21. Mukhin V.M., Gur'yanov V.V., Zubova I.D., Baranov A.M. Sposob Polucheniya Droblenogo Uglerodnogo Adsorbenta iz Polimernogo Syrya [Method of production of crushed carbon adsorbent from polymeric raw material]. Patent RU 2404919, publ. 27.11.2010. (Rus)

22. Barnakov Ch.N., Samarov A.V., Shikina N.V., Yakubik D.G. Strukturnye Osobennosti Mezoporistyh Uglerodnyh Materialov, Sintezirovannyh Shchelochnoj Karbonizaciej Smesej Fenol-furfurol i Gidrohinon-furfurol [Structural peculiarities of mesoporous carbon materials synthesized by alkaline carbonization of phenol-furfural and hydroquinone-furfural mixtures]. Khimiya $v$ interesakh ustoychivogo razvitiya, 2015, 2, 219-223. (Rus) 